Yet neither this storm-warning experience nor the existence of India's sophisticated seismic networks led to warnings being issued on 26 December, once the tsunami had struck the Andaman and Nicobar Islands. The tsunami did not hit the Indian mainland for another two hours. Allegedly, communications links had survived in Port Blair on the Andaman Islands, not to mention nearby airforce and navy bases that were affected. Some have argued that up to 40,000 people might have been saved if they had been warned. Further, India issued an incorrect warning a few days after the tsunami hit, triggering massive panic in India and Sri Lanka.

At the same meeting, India announced that it could develop new systems and models "based on end-to-end principles" in two years, using the best brains in India. For reference, the United States and Japan took more than 20 years to develop validated numerical models to predict tsunami evolution. And it took the US National Oceanic and Atmospheric Administration 30 years to fully develop its bottom-pressure recorders, which have been reliably detecting tsunamis for the past ten years.

India has an opportunity to establish a regional warning centre for the Indian ocean, thus ending its self-imposed isolation in sharing seismic data. It has the communications infrastructure and the scientific talent to serve its citizens and the international community. But the idea that India can do it alone is misguided.

Costas Synolakis

Department of Civil Engineering,

University of Southern California,

Los Angeles, California 90089-2531, USA

\section{Ethics and ethnoflora}

Sir - Pleased though we were to read the generous and thorough review of our book Ethnoflora of the Soqotra Archipelago in Nature ("Back to the roots" Nature 432, 805-806; 2004), we feel that — given the politically sensitive environment in which we work - we need to address the comment that "many ethical issues ... are not generally considered in this book".

We were scrupulous, for example, about informing all those who contributed to our book about their intellectual property rights. This was in strict compliance with the Convention on Biological Diversity (and with our contract). All informants recorded on tape, in Soqotri, their agreement and their understanding of the purpose of the research.

Regarding the recognition of intellectual contribution, our book includes a list of some 140 Soqotran contributors. (Female informants could not be named individually for cultural reasons.) And although Ethnoflora did not specifically mention any of the educational and capacity-building programmes in the archipelago in which we are involved, these activities are fully reported elsewhere.

Tony Miller*, Miranda Morris $\dagger$

${ }^{\star}$ Royal Botanic Garden, Inverleith Row,

Edinburgh EH3 5LR, UK

$\dagger$ School of History, University of St Andrews,

St Katherine's Lodge, The Scores,

St Andrews, Fife KY16 9AL, UK

\section{Biologists do not pose a threat to deep-sea vents}

Sir - Magnus Johnson suggests, in Correspondence ("Oceans need protection from scientists too" Nature 433, 105; 2005), that "uncoordinated and unregulated" research is one of the greatest threats to hydrothermal vent habitats. We offer information to the contrary. Furthermore, we suggest that the vent-research community is unusually well-organized internationally to examine the effects of researcher activities and to implement a code of conduct.

As with most field studies, it is possible to cite examples of overexuberant sampling, especially in the years following the discovery of vents. But potential effects of sampling were recognized early (V. J. Tunnicliffe Geophys. Res. 95, 12961-12966; 1990) and researchers at vents are proactive in developing mechanisms to reduce sampling effects.

Although it is true that the main effects on hydrothermal vents come from scientists because the only visitors at vents are scientists, today much more emphasis is placed on management and conservation to reduce the collection of organisms. Many known vents are no longer sampled and effort is concentrated at a few sites.

The current ethos of vent marine scientists is evident in the activities of the Biogeography of Chemosynthetic Ecosytems (ChEss) programme (www.soc. soton.ac.uk/chess) within the 'census of marine life' initiative. ChEss helped to convene a fact-finding workshop on hydrothermal ecosystems with the United Nations' International Seabed Authority (ISA) last September. The ISA is responsible for developing the legislation required to ensure and provide for responsible and sustainable activity throughout the world's deep-ocean environments. There is also a draft Code of Conduct pending approval by InterRidge (www.interridge.org), the office that coordinates international studies on mid-ocean ridges.

Canada's Endeavour Hot Vents Marine Protected Area, which Johnson highlights, was established with the strong support of scientists. Examine the website that Johnson cites to see that there are 'zones' of activities — including 'No Sample' areas. Johnson's comment that a senior scientist advised him not to complain is a sad one. Any discipline needs to keep its ears open to possible abuse as well as ensuring responsible reporting of the facts.

We have worked as scientists on many aspects of deep-sea oceanography for nearly 30 years and share all concerns about damage to that environment. The lessons we have learned at hydrothermal vents are ones that we now apply at other chemosynthetically driven ecosystems, such as cold seeps and whale falls.

Paul Tyler, Christopher German,

Verena Tunnicliffe

Southampton Oceanography Centre, University of Southampton, Southampton SO14 3ZH, UK

Signed on behalf of 18 international members of the ChEss

programme steering group

\section{Making sure corrections don't vanish online}

Sir - We have counted the numbers of errata, corrigenda, corrections and addenda published in all 2004 Nature print issues, across all sections of the journal. During the past year, Nature has reported flaws in 32 peer-reviewed research papers, of which 24 were corrigenda (author corrections) and 8 were errata (journal corrections); there were also 2 addenda. Although all these corrections were published last year, 14 of the erroneous papers were published before 2004 . Within the other sections of the journal there were 14 errors reported.

Worryingly, in 14 out of 34 cases Nature failed to attach an amendment page with the online PDF of the original paper. Nature has also failed to provide an amendment notice with the abstract or HTML version of several research papers (7 times out of 34). Similar problems arise for corrections to non-research items such as News stories.

With the widespread practice of accessing, printing and circulating PDF files through the Internet, it seems advisable to take this matter seriously. Eun-Hee Shim ${ }^{\star}$, Vishwas Parekh $\dagger$

${ }^{*}$ Department of Biochemistry,

$\dagger$ Department of Hematology-Oncology,

St Jude Children's Research Hospital,

Memphis, Tennessee 38105, USA

Corrections published in Nature should be linked online to the article being corrected, both in the text of the correction and in the HTML of the original article. The articles identified by Shim and Parekh have now been linked in this way. Editor, Nature 